\title{
Opinion: Coordinated Development of Emission Inventories for Climate Forcers and Air Pollutants
}

\author{
Steven J. Smith ${ }^{1}$, Erin E. McDuffie ${ }^{2}$, Molly Charles ${ }^{1}$ \\ 1 Joint Global Change Research Institute, Pacific Northwest National Laboratory, College Park, MD. \\ 52 AAAS Science and Technology Policy Fellowships, Washington, D.C.
}

Correspondence to: Steven J Smith (ssmith@,pnnl.gov), Erin McDuffie (ㄹin.mcduffie@wustl.edu)

\begin{abstract}
Emissions into the atmosphere of fine particulates, their precursors, and precursors to tropospheric ozone, not only impact human health and ecosystems, but also impact the climate by altering Earth's radiative balance. Accurately quantifying these impacts across local to global scales,

10 historically, and in future scenarios, requires emission inventories that are accurate, transparent, complete, comparable, and consistent. In an effort to better quantify the emissions and impacts of these pollutants, also called short-lived climate forcers (SLCFs), the Intergovernmental Panel on Climate Change (IPCC) is developing a new SLCF emissions methodology report. This report would supplement existing IPCC reporting guidance on greenhouse gas (GHG) emissions inventories,

15 currently used by inventory compilers to fulfill national reporting requirements under the United Nations Framework Convention on Climate Change (UNFCCC) and new requirements of the Enhanced Transparency Framework (ETF) under the Paris Agreement starting in 2024. We review the relevant issues, including how air pollutant and GHG inventory activities have historically been structured, as well as potential benefits, challenges, and recommendations for coordinating GHG and air pollutant

20 inventory efforts. We argue that while there are potential benefits to increasing coordination between air pollutant and GHG inventory development efforts, we also caution that there are differences in appropriate methodologies and applications that must jointly be considered.
\end{abstract}

\section{Introduction}

Anthropogenic emissions of gases and particulates into the atmosphere have wide-reaching impacts that

25 span local to global scales. For example, emissions of short-lived air pollutant species such as sulfur dioxide $\left(\mathrm{SO}_{2}\right)$, carbonaceous aerosol, and other products of incomplete combustion cause enhanced levels of fine particulate matter and surface level ozone $\left(\mathrm{O}_{3}\right)$, both of which are harmful to human health and ecosystems (Mannucci et al., 2015). In contrast, emissions of greenhouse gases (GHG), such as methane $\left(\mathrm{CH}_{4}\right)$ and carbon dioxide $\left(\mathrm{CO}_{2}\right)$ are longer-lived in the atmosphere and alter the Earth's

30 radiative balance, termed radiative forcing, leading to anthropogenic climate change (Myhre et al., 2013). 
These classifications, however, are not always distinct as the same compounds that contribute to poor air quality can also impact Earth's radiative budget. For example, ambient fine particulate matter is the world's leading environmental health risk factor, responsible for roughly 4 million deaths worldwide in 2019 (GBD 2019 Risk Factor Collaborators, 2020), but also impacts Earth's radiative balance, historically with a net cooling effect (Naik et al. 2021). This cooling effect is sufficiently strong that historical climate patterns cannot be reproduced without including these effects in models (Barnett et al., 1999; Stone et al., 2009). In addition, $\mathrm{O}_{3}$ in the troposphere, enhanced in the presence of sunlight and air pollutant emissions, is also damaging to both environmental and human health, and is a GHG that contributes to anthropogenic climate change. Emissions of these compounds and their precursors rapidly increased during the course of the $20^{\text {th }}$ century (Hoesly et al., 2018), but in recent years have both increased and decreased, depending on the specific region and individual compound ( $\mathrm{O}$ 'Rourke et al. 2021).

Inventories of air pollutant and GHG emissions help to better understand, quantify, and manage the net impacts of these compounds, thereby serving as a central tool for scientific and policy activities. Inventories quantify the rate of emissions of individual compounds into the atmosphere from specific processes or activities. They are generally based on bottom-up calculations that require detailed information on emission factors and activity data, such as fuel consumption or vehicle miles traveled, but can also incorporate direct measurements or results from physical process models. Scientific computational models rely on these inventories as inputs, in order to simulate and study atmospheric processes or global change. Emission inventories that are complete (include emissions from all major sources and regions), accurate, and developed using consistent, transparent, and comparable methodologies also provide fundamental data to inform policy decisions and allow for the evaluation of mitigation activities. For example, air pollutant and GHG emission inventories can be used within a suite of tools to identify activities that lead to unhealthy air pollution levels or to inform or verify policies intended to mitigate air pollution or climate change.

While having similar applications, the development of national air pollutant and GHG inventories, have been historically distinct. For example, inventories of air pollutant emissions have historically been developed by individual governments to support national and multilateral efforts to reduce air pollutant levels. While there is currently no globally consistent framework for reporting national inventories of air pollutant emissions, national and regional inventory activities have been underway since the 1970s in North America and Europe, with air pollutant inventory activities now well established in many countries around the world. As a result, in large part due to air pollution control efforts informed by these inventories, emission levels for most air pollutants have been generally decreasing in North

65 America and Europe since the early 1980s, which has been broadly reflected in both inventory and observational data (Hoesly et al., 2018; Xing et al., 2015; Hand et al., 2012). This pattern has been repeated more recently in China, with air pollution control actions also resulting in substantial emissions reductions in China for some air pollutants within the last decade (Zheng et al., 2018b).

In contrast to air pollutant inventories, national efforts to quantify emissions of GHGs have been

70 developed more recently and largely follow more standardized methodologies. For example, under the United Nations Framework Convention on Climate Change (UNFCCC; https://unfccc.int) 197 
signatories agreed to report annual inventories of their national anthropogenic GHG emissions and sinks using comparable methodologies. This agreement was a fundamental step in facilitating multilateral cooperation to address climate change. Under the UNFCCC, annual emission inventory reporting is mandatory for "Annex I" countries ${ }^{1}$ starting with emissions in 1990 up to the current year minus two, and requires that countries use IPCC Guidelines for National Greenhouse Gas Inventories (IPCC, 2006) to develop emission estimates. The first national inventories were submitted to the UNFCCC in the early 1990s. More recently as part of the reporting requirements of the Enhanced Transparency Framework (ETF) under the Paris Agreement, Annex I countries are still required to report annual anthropogenic GHG inventories, but developing countries will have new requirements to submit national GHG inventories at least every two years, starting in the year 2024. All countries will be required to report emissions following 'good practice' GHG methodologies detailed in the 2006 IPCC GHG methodology reports.

As a follow-on to the IPCC GHG methodology guidelines and to address uncertainties in SLCF 85 emissions and their impacts, the IPCC recently directed its Task Force on National Greenhouse Gas Inventories (TFI) to produce an IPCC methodology report on Short-lived Climate Forcers (Decision IPCC-XLIX-7, May 2019). The addition of this report is intended to facilitate the estimation of both national air pollutant and GHG emissions. The TFI is currently gathering information on existing air pollutant inventory methods, in consultation with international inventory experts, to help inform an

90 outline for the methodology report. Pending approval of the outline by the Panel, the development of the full SLCF methodology report is currently planned to commence during the seventh IPCC assessment report (AR7) cycle.

In this perspective, we provide a background and discussion on the similarities and differences between inventories of air pollutant and GHG emissions (Figure 1). For both air pollutants and GHGs, we

95 include a summary of their health and environmental impacts, present differences in the historical use and development of GHG and air pollution emission inventories, and discuss distinct inventory data needs and emission uncertainty considerations. In the third section we discuss unique characteristics of "SLCF inventories" as well as approaches and considerations for quantifying the net health and climate impacts of these compounds. In the last section we argue for the benefits of developing a coordinated framework to jointly estimate GHG and air pollutant emission inventories, but also discuss the associated challenges. We end with a summary of recommendations for organizations, compilers, and research groups interested in such activities.

1 Annex I Parties include the industrialized countries that were members of the OECD (Organization for Economic Co-operation and Development) in 1992, plus countries with economies in transition (the EIT Parties), including the Russian Federation, the Baltic States, and several Central and Eastern European States. 


\section{Air Pollutant Emissions}

\subsection{Impacts}

105 Long-term exposure to indoor and outdoor air pollution was attributable to nearly 7 million deaths worldwide in the year 2019, corresponding to the loss of over 213 million disability-adjusted life-years (GBD 2019 Risk Factor Collaborators, 2020). This global burden, however, is not uniformly distributed across all countries, with air pollution-attributable mortalities generally much higher in low to middle income countries (generally upper right in Figure 2). The main sources of air pollution in each region differ as well (McDuffie et al., 2021). A much larger fraction of pollutant emissions in lower income countries originate from solid biofuel use and open burning, while sources shift to predominantly fossil fuel combustion in high Socio-Demographic Index (SDI) countries (GBD 2019 Risk Factor Collaborators, 2020).

Economic development in lower income countries also presents a unique air quality challenge. The 115 historical trajectories shown in Figure 2 illustrate that low to middle SDI countries generally move leftward over time as economic activity expands. Air pollution levels remain high as fossil fuel use increases and eventually dominates over solid biomass fuels in these regions. As incomes continue to increase and once control policies are instituted, countries generally move downward in Figure 2 to lower levels of air pollution and attributable deaths (1-8\% in high SDI countries after 2015). Therefore, from an air pollution perspective, a key development challenge in lower income countries is to accelerate the transition to lower air pollutant levels and mortality, while also improving living standards.

\subsection{Inventory Compounds}

Inventories of air pollutants include emissions of compounds that are directly hazardous to human

125 health, such as nitrogen oxides $\left(\mathrm{NO}_{\mathrm{x}}=\mathrm{NO}_{2}+\mathrm{NO}\right)$ and primary aerosol. These inventories also generally include gaseous ammonia $\left(\mathrm{NH}_{3}\right)$, carbon monoxide $(\mathrm{CO})$, non-methane volatile organic compounds (NMVOCs), and $\mathrm{SO}_{2}$, which are precursors to tropospheric $\mathrm{O}_{3}$ and secondary particulate matter. These compounds are emitted from a wide variety of sources including fuel combustion for energy generation and transportation, agricultural practices, as well as industrial processes, solvent use, and waste disposal. As described below, emission estimation methods for each compound can vary by source and region, and in many cases require detailed source, temporal, and spatial information. Note that primary aerosol emissions in air pollutant inventories are often enumerated as $\mathrm{PM}_{2.5}$ (particles smaller than 2.5 micrometers in diameter) and $\mathrm{PM}_{10}$, but for inventories intended for use in climate models are enumerated as black carbon (BC) and organic carbon (OC), which are major components of $\mathrm{PM}_{2.5}$ emissions. Some inventories include emissions of both total $\mathrm{PM}_{2.5}$ as as well $\mathrm{BC}$ and $\mathrm{OC}$.

\subsection{Historical Inventory Use and Development}

In contrast to GHG inventories (Section 3), there is no globally consistent framework for reporting national emission inventories of air pollutants. As a result, the use and development of air pollutant 
emission inventories will often vary between regions due to geographical differences in the relative sources, available resources for emissions reporting and mitigation, and the relative impacts of air pollutants and their precursors.

For example, in lower income regions, where air pollution accounted for an average of $16 \%$ of all air pollution-attributable deaths in 2019 (Low and Low-middle SDI in Figure 2), the largest near-term gains in air quality will often come from large-scale transformations focused on reducing open burning (agricultural field burning, forest and grassland burning) and the household use of traditional solid biofuels and coal. In these countries, however, the availability of detailed inventory data is not necessarily a pre-requisite for effective large-scale action. China provides an interesting example in this respect. Over the last two decades, there was no formal government process in place for air pollutant emission inventory development. The de-facto official air pollutant inventories were instead produced by university research groups, albeit with close ties and cooperation with government ministries. Throughout this same time period, there was increased focus on improving air quality in China, with strict controls on electric power plants and, more recently, large industrial boilers, and emission standards for new vehicles. The result was decreasing $\mathrm{SO}_{2}$ and $\mathrm{NO}_{\mathrm{x}}$ emissions (Zheng et al., 2018a) by the mid 2010s. Publication of an air pollutant emissions inventory in 2018 illustrated, in retrospect, the significant declines in emissions, and helped to evaluate the impact of these controls after many of these ambitious policy actions had already taken effect (Zheng et al., 2018a).

In high income countries (high SDI), where air pollution accounted for an average of $3 \%$ of all attributable deaths in the year 2019 (left in Fig 2), the use of air pollutant inventories is more central to the policy process. Improving air quality is often a more nuanced process in these countries where

160 significant air pollution controls are already in place. Here, emission inventories are used as a tool to help reach compliance goals, guide mitigation actions, and as input data for air quality modeling. In these countries the ultimate regulatory end points are measured pollutant concentrations, which are required to be below specified thresholds for a designated period for a region to be considered in regulatory compliance. Another key issue is the effect of local emissions on pollutant concentrations downwind and the potential for localities within a country to have differing compliance status. As a result, detailed air pollutant inventories are regularly produced, often with a focus on higher levels of spatial and temporal detail, including characterization of emissions during short periods where air pollution exceeds regulatory limits. Indeed, the term "inventory" in the air pollution community is often taken to be synonymous with these detailed spatial emissions data. Emission inventories, however, are only one part of regulatory, mitigation, and modeling activities, which must also contend with uncertainties in the split between natural and anthropogenic emission sources, as well as our evolving understanding of atmospheric processes that lead to the production of pollutants, their deposition, and downwind transport.

In high SDI countries, air pollutant inventories also can be used in air pollutant trading or emissions cap programs across jurisdictional boundaries, particularly for the acidifying sulfur and nitrogen dioxide species. In large part because of these regulatory programs, emissions for large sources are directly measured in the United States and Canada, and it is these measurements that form the basis of subsequent inventories for these sources instead of bottom-up calculations. In Europe, country-level 
emissions targets have been negotiated under the Gothenburg protocol, making inventory estimates central to this process as well.

\subsection{Data Needs}

The development of emissions data used as part of regulatory processes in high SDI countries is often supported by ministries and consultancies that specialize in the production of air pollutant emission inventories. Further, these inventories are made possible by the availability of voluminous ancillary data such as statistics on energy consumption, road networks, vehicle counts along highways, and economic and industrial activity. Many country inventories rely heavily on extensive reporting processes by states/provinces and individual facilities. Because some air pollutant emissions can also have a large dependence on operational conditions, including the performance of emission control devices, there are substantial analysis and data needs for accurate air pollutant emission estimates.

190 These data needs and development processes in high SDI countries contrast with lower income countries where, the technical infrastructure and resources needed for inventory development are often limited, and the data needed to support detailed inventory development may not exist. For example, to estimate emissions from road vehicles, either the amount of fuel consumed, or vehicle-distance traveled by different vehicle categories (freight trucks, passenger cars, buses, etc.) needs to be known. This information is not available for many countries.

In light of these data and resource limitations, the type of information most needed to inform air quality policies should be prioritized based on the policy context, resources, and circumstances in each country or entity. In low income countries, for example, ongoing efforts to improve energy access by providing on-demand lighting will lower mortality rates and improve livelihoods by reducing air pollution

200 exposure and lowering the time burden of solid biofuel collection. These efforts are comparable, in broad goals, to the rural electrification program in the United States from the late 1930s. In this example, a key metric for progress might be prioritizing data collection on the use of polluting fuels, (e.g., traditional biofuels, kerosene for lighting), their trends, and their cleaner replacements (electricity for lighting, liquified petroleum gas for cooking, and use of improved cookstoves).

205 Further, inventory development will need to be prioritized based on dominant local sources and current trends. While similar in concept to the IPCC key category analysis for GHG emissions (see below), prioritization can be more complex for air pollutants. For example, China and India are rapidly adopting road vehicle emission standards similar to those in the North America and Europe. This can result in a faster movement to higher vehicle control levels in these countries, which stands in contrast to the 210 decades long process in the United States and Europe, of increasingly strict standards that proceeded together with technological developments to facilitate improved emission control devices. This means that over the coming years, if most vehicles become compliant with higher standards, highly detailed inventories of air pollutant emissions from road vehicles could become less relevant for the development of new air pollution mitigation policies. However, it will be important to track compliance 215 rates, as well as usage rates for older vehicles, since, once the majority of vehicles are equipped with strong emission controls, road vehicle emissions will be increasingly impacted by super-emitters 
(Carslaw et al., 2011). This means that, while ensuring compliance will be important, air pollutant inventory efforts in the future may best be focused on sectors and subsectors (e.g., off-road mobile sources in the USA) or specific emitted compounds (e.g., NMVOCs in China) that have become relatively larger contributors to air pollution.

\subsection{Uncertainty}

There has been limited focus on estimating uncertainties in air pollutant inventories used by regulatory agencies. Particularly as emission levels fall, greater focus on estimating uncertainty will be helpful to better understand where estimated emissions may need improvement, given that incorrect emissions data could mischaracterize trends or lead to sub-optimal policy choices. As an example, observational and modeling analyses have indicated that there appear to be biases in United States and European air pollutant inventory estimates for mobile sources that need to be addressed (Carslaw et al., 2011; Anenberg et al., 2017; Anderson et al., 2014; Hassler et al., 2016), even with the extensive emission estimation processes currently in place. This is indicative of the difficulty of making accurate estimates

230 for some emission sectors and highlights the need to review the detailed assumptions and procedures used to estimate these emissions, understand sources of uncertainty, and to make use of observational data for inventory evaluation.

Qualitatively, emission uncertainty is often higher in developing countries due to gaps in activity data and a lack of emission factor information appropriate for local technologies and usage patterns.

235 Quantifying emissions from household solid biofuel use, for example, has proven to be particularly difficult with large uncertainties. Not only is residential biofuel consumption uncertain, with current global energy datasets populated with model estimates for many lower-income countries, but laboratory emission factor measurements do not replicate varied real-world operational conditions, and in-situ measurements are difficult to undertake. While this results in a significant level of uncertainty in pollutant emissions from this source, given the solid evidence of the resulting impacts on human health, this uncertainty does not detract from the overall rationale for expanding energy access Therefore, while emission uncertainty needs to be recognized, uncertainty is not necessarily an impediment to effective pollution mitigation action.

\section{Greenhouse Gas Emissions}

\section{$245 \quad 3.1$ Impacts}

The context changes significantly when considering greenhouse gases rather than air pollutant compounds. Most GHG emissions become well-mixed into the atmosphere which means that the location of emissions is largely decoupled from their impact on the Earth system. The time horizon for climate change is also longer, given both the global scope of fossil-fuel consumption and the century to millennial atmospheric time scales of the carbon-cycle. This means that GHG emissions and concentrations are a global and long-term issue. Further, in contrast with air pollutants, atmospheric concentrations of GHGs are not particularly useful as near-term regulatory end-points, as concentrations 
change slowly and are influenced by short-term variations in the carbon-cycle and atmospheric chemistry. ${ }^{2}$ Instead, GHG emission inventories are the central tools for tracking emission trends and mitigation progress, such as those submitted regularly to the UNFCCC, which are key indicators of progress toward meeting national GHG emission reduction goals.

\subsection{Inventory Compounds}

Inventories of GHGs include carbon dioxide $\left(\mathrm{CO}_{2}\right)$, methane $\left(\mathrm{CH}_{4}\right)$, nitrous oxide $\left(\mathrm{N}_{2} \mathrm{O}\right)$, as well as fluorinated gases (F-gases). Fossil $\mathrm{CO}_{2}$ emissions are the most straightforward to quantify because emissions can be estimated from statistics on net fossil fuel consumption and fuel energy content. Fossil $\mathrm{CO}_{2}$ emissions are the largest portion of anthropogenic GHG emissions both globally, $72 \%$ of global GHG emissions in 2018 (Minx et al. 2021, excluding $\mathrm{CO}_{2}$ from land-use change), and for most large countries. A robust estimate of $\mathrm{CO}_{2}$ emissions, therefore, provides for a solid foundation for total GHG emission estimates.

265 Methane and $\mathrm{N}_{2} \mathrm{O}$ are the next most important GHGs. These emissions originate largely from either fugitive sources or through biological processes such as anerobic decomposition and soil nitrogen cycles, making them inherently more uncertain. Fugitive emissions are also challenging to estimate and have large uncertainties since conditions vary spatially and temporally and a small number of sources can dominate the total emissions within a sector.. Zimmerle et al. (2015) estimate, for example, that uncertainty in fugitive $\mathrm{CH}_{4}$ emissions from the transmission and storage of natural gas in the United States is $+36 \% /-23 \%(+30 \% /+19 \%$ if unmodeled portions of the sector are included $)$, and that over $36 \%$ of emissions from this sector are from a small number of individual sources. Note, however, that fugitive sources are not often dominant sources of total national anthropogenic GHG emissions. As estimated by the global EDGAR GHG inventory (Minx et al. 2021, Crippa et al. 2021), fugitive $\mathrm{CH}_{4}$ emissions from oil and gas operations were less than $20 \%$ of total national $\mathrm{CH}_{4}$ emissions in 86 of the top 100 GHG emitting countries in 2015.

Fluorinated gases are the remaining category of GHGs, which have industrial uses including as refrigerants, foam blowing agents, insulators in high voltage electrical equipment, and in other processes. Because most of these gases have no natural sources, total emissions globally or, in some cases over large regions, can be estimated using atmospheric concentration measurements, although understanding which sources contribute still requires emission inventories.

\subsection{Historical Inventory Use and Development}

In contrast with air pollutant inventories, the use and development of GHG emission inventories over the last three decades has been strongly influenced by international reporting requirements. For example, the UNFCCC (ratified by 197 countries) requires the development and reporting of accurate,

\footnotetext{
2 It is also possible to estimate GHG emissions from concentration measurements, from either surface stations, aircraft, and/or satellites. Such inversion estimates can also play a role, particularly in identifying particularly large sources and identifying regions where inventories may have large biases.
} 
complete, consistent, comparable, and transparent annual anthropogenic GHG emission and removal estimates. Emissions reporting is facilitated by detailed templates and methodological guidelines from the IPCC (i.e., IPCC inventory guidelines). These emission methodologies are divided into three tiers, with higher tier methods requiring more detailed information, but also having a higher presumed accuracy. It is recommended that the higher tier methods be used for source categories that are large or quickly growing in a particular country. There is also a focus on obtaining consistent emission trends over time, given that these are a key metric for measuring progress towards GHG reduction goals. For this reason, as data or methods are revised, it is IPCC "good practice" for countries to re-estimate emissions over the entire reporting period (base year forward). We note that this sort of past reestimation is not common for air pollutant emissions.

For parties included in Annex I to the Convention (Annex I Parties), annual GHG inventories require anthropogenic emissions and removals of GHGs $\left(\mathrm{CO}_{2}, \mathrm{CH}_{4}, \mathrm{~N}_{2} \mathrm{O}\right.$, perfluorocarbons (PFCs), hydrofluorocarbons (HFCs), sulphur hexafluoride (SF6), and nitrogen trifluoride $\left(\mathrm{NF}_{3}\right)$ ) from five sectors (energy; industrial processes and product use; agriculture; land use, land-use change and forestry

300 (LULUCF); and waste). The current UNFCCC reporting guidelines on annual inventories for these Parties include use of the 2006 IPCC Guidelines for National Greenhouse Gas Inventories and subsequent refinements (IPCC, 2019).

Reporting for Non-Annex I Parties (mostly developing countries) under the UNFCCC is currently less detailed and is implemented through national communications (NCs) and biennial update reports (BURs). NCs provide information on GHG inventories and are submitted every four years. BURs provide an update of the information presented in NCs, in particular on national GHG inventories and are submitted every two years as a summary of their NC or a stand-alone report. The Non-Annex I Parties national inventories of anthropogenic emissions should include sources and removals by sinks of all greenhouse gases not controlled by the Montreal Protocol, to the extent national capacities permit, using comparable methodologies to be promoted and agreed upon by the Conference of the Parties.

In the more recent Paris Agreement, the distinction between Annex I / Non Annex I Parties is removed and in its place is the establishment of the Enhanced Transparency Framework (ETF) for all Parties under the commitment. Under the ETF, starting in the year 2024, each Party shall regularly provide a national inventory report of anthropogenic emissions and removals of greenhouse gases, submitted 315 using Common Reporting Tables, and prepared using good practice methodologies from the 2006 IPCC inventory guidelines, as well as information necessary to track progress made in implementing and achieving its nationally determined contribution (NDC) GHG target.

\subsection{Data Needs}

Under UNFCCC requirements, each country reports their national inventory of anthropogenic GHG 320 emissions to the UNFCCC secretariat. Within this framework, the development of GHG emissions data in Annex I (generally high SDI) countries is often supported by ministries and consultancies that specialize in the production of GHG emission inventories. These groups, however, are not always the same as those that lead the development of air pollutant inventories. Similar to air pollutant inventories, 
however, GHG inventories also rely on voluminous ancillary datasets, including energy and infrastructure statistics. As fossil $\mathrm{CO}_{2}$ emissions are typically a major source of national GHG emissions, complete and accurate energy consumption statistics are key data needed for GHG emission inventories. Increasingly detailed activity and emission factor data at the sub-national and facility-level are also required when implementing higher tier IPCC methods. It is recommended by the IPCC that a country implement higher tier methods for key categories ${ }^{3}$ within their inventory and to use these

330 categories to prioritize national resources for data collection and inventory compilation and reporting. In developing countries, data and resource limitations present a similar challenge as those for air pollutant inventories, however the IPCC GHG inventory guidelines provide tier 1 methods and default emission factors, with the intent of making it feasible for all countries to develop their own national GHG inventory.

335 Also in contrast with air pollutant inventories, the historical focus of GHG inventory reporting has been on estimating annual national level emissions. This is largely because the temporal and spatial variability of GHG emissions is not relevant to their climatic impacts. Outside of the UNFCCC framework, GHG inventories at the state/province and city level are increasingly being produced so that jurisdictions can also track their progress toward emission reduction goals (Ibrahim et al., 2012). More spatially detailed GHG inventories can also be used to compare inventories with atmospheric observations. These inventories require increasingly detailed underlying inputs or the use of proxy datasets to allocate national or state-level inventories to finer spatial and temporal resolution.

\subsection{Uncertainty}

The IPCC GHG guidelines also provide methodologies for estimating emission uncertainties, which are 345 required in national inventories submitted by Annex I countries. The IPCC provides two approaches for estimating sector and compound-specific uncertainties. The choice of using approach depends on the distribution shape of the uncertainties in underlying input activity and emission factor data and the details of the specific emission methods used. Neither approach, however, can capture all sources of uncertainty and as with air pollutant emissions, total inventory uncertainties are likely higher in countries with limited data. Regardless, uncertainty estimates are a valuable guide to inventory development because they point to areas where data and methodological improvements are needed most. It is likely that, because GHG inventories use more homogenous methodologies as compared to air pollutant inventories, uncertainty analysis is more tractable.

\section{Short-Lived Climate Forcers}

355 A major link between air pollution and climate change is through the emissions of Short-Lived Climate Forcers (SLCFs), which are generally defined as aerosols, tropospheric $\mathrm{O}_{3}$ precursor compounds, $\mathrm{CH}_{4}$,

${ }^{3}$ Key categories are emission categories that have a significant influence on a country's total inventory of greenhouse gases in terms of the absolute level of emissions and removals, the trend in emissions and removals, or uncertainty in emissions and removals. 
and shorter-lifetime hydrofluorocarbons (HFCs). There is, therefore, no distinct "SLCF inventory" distinct from air pollutants or GHGs, but is more a matter of context, given that all conventional air pollutant emissions are also SLCFs. As a result, "SLCF inventory" development and data needs are already reflected in the air pollutant emissions section above.

We focus this section on those air pollutants that also impact climate, which will be considered in an upcoming IPCC SLCF Methodology Report. We note that the term "air pollutants" can include additional categories of emissions such as heavy metals and toxic compounds, such as benzene and perchloroethylene that are "known or suspected to cause cancer or other serious health effects" (called Hazardous Air Pollutants in the U.S.). ${ }^{4}$ In this section we are instead discussing "air pollutant SLCFs" considered by the IPCC, which include $\mathrm{BC}$ and $\mathrm{OC}$, as well as $\mathrm{SO}_{2}, \mathrm{NH}_{3}, \mathrm{NO}_{\mathrm{x}}, \mathrm{CO}$, and $\mathrm{NMVOCs}$, which each uniquely impact the formation of particulate matter and tropospheric $\mathrm{O}_{3}$.

For these compounds, the relationship between emissions, climate, and air pollution is complex and often non-linear. For particulate matter, for example, while most individual components have a net cooling effect (sulfates, nitrates, and OC), BC (or soot) has an opposite warming effect. Therefore, while atmospheric aerosols are estimated to have a net cooling effect on the climate, reducing emissions to improve air quality could "unmask" GHG warming that had previously been offset (Lelieveld et al., 2019). In addition, with a lifetime in the atmosphere of roughly a week, the distribution of aerosol concentrations has a strong dependance on the spatial distribution of emissions, which is in contrast 375 with GHG concentrations.

Understanding the net impact of reactive gas emissions is even more complex. For example, when considering their net radiative impacts, emissions of $\mathrm{NO}_{\mathrm{x}}, \mathrm{CO}$, and $\mathrm{NMVOCs}$ not only impact atmospheric concentrations of $\mathrm{CH}_{4}$ and $\mathrm{O}_{3}$, but changes in $\mathrm{CH}_{4}$ concentrations will then feedback to impact background $\mathrm{O}_{3}$ levels. In addition, due to non-linearities in atmospheric chemistry, changes in $\mathrm{NO}_{\mathrm{x}}$ and $\mathrm{NMVOC}$ emissions can either increase or decrease local $\mathrm{O}_{3}$ concentrations, depending on background conditions and the relative emissions of each. In China, for example, recent reductions in $\mathrm{SO}_{2}$ and $\mathrm{NO}_{\mathrm{x}}$ emissions reduced particulate matter concentrations, however, $\mathrm{O}_{3}$ levels appear to have increased because emissions of NMVOCs were not reduced at the same time (Liu and Wang, 2020). In terms of the global climate, emissions of $\mathrm{CH}_{4}, \mathrm{CO}$, and NMVOCs have increased the historical forcing

385 from both $\mathrm{CH}_{4}$ and background tropospheric $\mathrm{O}_{3}$ (Myhre et al., 2013). Increased $\mathrm{NO}_{x}$ emissions, however, have decreased $\mathrm{CH}_{4}$ forcing (by decreasing $\mathrm{CH}_{4}$ lifetime) but have increased background $\mathrm{O}_{3}$ forcing, with the decrease in $\mathrm{CH}_{4}$ forcing estimated to be larger.

Tropospheric $\mathrm{O}_{3}$ itself is also complex as it is both a health hazard and a GHG. While this means that reducing tropospheric $\mathrm{O}_{3}$, on a global level, is a "win win" for both air pollution and climate, the

390 impacts of $\mathrm{O}_{3}$ occur across differing spatial and temporal scales. For air quality, most attention is focused on polluted areas with high seasonal and/or peak $\mathrm{O}_{3}$ levels. In contrast, $\mathrm{O}_{3} \mathrm{GHG}$ forcing is not driven by areas of peak concentrations, but by the larger-scale background $\mathrm{O}_{3}$ level. As mentioned

${ }^{4}$ https://www.epa.gov/haps/what-are-hazardous-air-pollutants. Accessed October 25, 2021 
above, local concentrations will largely depend on relative emissions of $\mathrm{NO}_{\mathrm{x}}$ and $\mathrm{NMVOC}$ precursors, while background $\mathrm{O}_{3}$ is determined largely by the magnitude of $\mathrm{CH}_{4}$ and $\mathrm{NO}_{\mathrm{x}}$ emissions.

395 An additional complication is that the forcing effects of individual non-GHG SLCFs are much more uncertain than those of GHGs. The relative impact of $\mathrm{CO}_{2}$ as compared to $\mathrm{CH}_{4}$ concentrations, for example, is much better constrained (even considering recent methane forcing updates, Etminan et al., 2016) than the radiative impact of aerosols, either collectively or for individual components. The impact of BC is particularly uncertain, in large part because of the dynamics that stem from BC heating within the atmospheric column (Stjern et al., 2017) and warming caused by darkening snow- and ice-covered areas, which is also uncertain. There are also substantial uncertainties in atmospheric chemistry calculations of the net impact of precursor compounds on $\mathrm{O}_{3}$ concentrations.

To capture these complex relationships between emissions, climate, and air pollution, and to inform or evaluate mitigation strategies, the climate impacts of air pollutant emissions are generally estimated by using air pollutant inventories as inputs into global atmospheric models (Stevenson et. al 2020). These are often the same models used to project the consequences of future GHG emission trajectories (O'Neill et al., 2016). Similar models are also used to examine the environmental and health impacts of these emissions, although models used for these purposes may have more detailed representations of atmospheric chemistry than those used for long-term simulations of climate change. Air pollutant

410 emissions data for both types of modeling are needed with greater spatial and temporal detail as compared to $\mathrm{CO}_{2}, \mathrm{CH}_{4}$, and F-gas emissions, with horizontal resolutions of roughly $50-100 \mathrm{~km}$ for global analyses (Feng et al., 2020). High resolution spatial emissions data is particularly important for analyses at regional to city-scales, although additional detail likely needs to be added to global emission datasets for finer-scale analysis (Huneeus et al., 2020).

415 When using these types of tools to evaluate the net impacts of a new technology or mitigation strategy, it is important to acknowledge the substantial uncertainty in the climate impacts of air pollutants. For example, many modeling studies have shown that reducing emissions from solid biofuel combustion for cooking and heating in the residential sector can improve air quality and avoid hundreds of thousands of attributable deaths in many densely populated regions throughout the world (e.g., McDuffie et al.,

420 2021). However, the net climate impact of reducing biofuel use in buildings appears to be small, due to offsetting heating and cooling effects (e.g., BC vs OC), with a large uncertainty range that may even include a slight warming (Smith and Mizrahi, 2013). While the climate and health effects of BC emission reductions from the transport sector are less ambiguous (at least under the assumption that diesel fuel is desulfurized) because of the predominance of BC emissions as compared to OC, there is still significant uncertainty in the overall magnitude of impacts.

In addition to uncertainties in net impacts, there are also uncertainties in the emission estimates themselves. As discussed above for air pollutant inventories, uncertainty estimates for air pollutants would be useful but are methodologically challenging in ways that can be distinct from GHG emissions. For example, for $\mathrm{BC}, \mathrm{OC}$, and $\mathrm{NMVOC}$ emissions, there are not only uncertainties in the magnitude of total emissions but also in the partitioning between $\mathrm{BC}$ and $\mathrm{OC}$, and a multitude of different volatile 
organic compounds (termed speciation). Uncertainty in speciation adds to the uncertainty in climate and health impacts of sources that emit these compounds.

While there has recently been significant interest in incorporating air pollutants into climate mitigation efforts, emission and modeling uncertainties mean that the net climate and health impacts of air pollutant emissions may change substantially as scientific knowledge advances. These uncertainties pose challenges to integrating air pollutant and greenhouse gas mitigation efforts and need to be considered to produce robust policies.

\section{Benefits and challenges of coordinating air pollutant and GHG emission inventory activities}

As a result of wide-ranging health and environmental impacts of air pollutant "SLCF" emissions and to facilitate consistent, transparent, comparable, accurate, and complete emission estimates, the IPCC recently directed its Task Force on National Greenhouse Gas Inventories (TFI) to produce an additional IPCC Methodology Report on SLCFs (Decision IPCC-XLIX-7, May 2019). Additional SLCF-focused guidelines may help to coordinate air pollutant and GHG inventory methodological approaches and could enhance the ability to consider synergies between both air pollution and GHG mitigation

445 strategies. In this context, we are considering inventory coordination to be the co-development of GHG and air pollutant inventories (not necessarily by the same team) that include regularly reported anthropogenic emissions for a common set of sources and compounds, using consistent underlying activity data and methodologies, where appropriate. This coordination would be most straightforward for common emitting activities with similar underlying driver data for both types of emissions (e.g., power plants), but would need to be considered more carefully in other cases, such as emissions related to land-use and land-use change.

Additional benefits of coordinated air pollutant and GHG inventory efforts could include the development of common reporting and/or methodological standards for air pollutant emissions that do not always exist at present. For countries without well-developed emission inventory systems, it may also be efficient to build a single coordinated system for estimating both GHG and air pollutant emissions. Increased coordination may also facilitate productive engagement between research groups and GHG and air pollutant inventory compilers that could lead to community-wide efforts to better align emission source definitions, methodological approaches, and facilitate additional data collection that could be used to improve emission inventories for both scientific and policy-oriented analyses (Janssens-Maenhout et al., 2015; Hoesly et al., 2018; Perugini et al., 2021). Similarly, existing workflows developed for producing spatially distributed (gridded) air pollutant inventories could facilitate the production of gridded GHG inventory data. These spatially explicit emissions are necessary for atmospheric modeling and are a useful tool for comparisons between regional and observationally informed emission estimates (e.g., Maasakkers et. al. 2016), as discussed in the 2019 465 Refinements to the IPCC GHG Guidelines (IPCC, 2019).

Challenges in coordinated development efforts, however, must also be considered. These largely arise from the different end uses of air pollutant (SLCF) and GHG emissions data. For example, because of 
their use for air pollutant impact and regulatory analyses, air pollutant-focused inventory development would also need to consider the spatial and temporal variability in underlying activity and emission factor data needed to capture variability in emissions. This is not the case for GHG emissions, where aggregate annual national-level emission factors and fuel consumption statistics are often sufficient to track national mitigation efforts. Therefore, in a coordinated GHG/air pollutant inventory system, the timing of inventory development may be distinct between GHG and air pollutant emissions as national fuel consumption statistics are often updated more quickly than sub-national data. Similarly, air pollutant methodologies can be more data intensive and, therefore, can have longer lag times. For example, mobile sources in the United States are estimated using the MOVES model, which requires a more detailed set of input data (far more data than required for estimating national GHG emissions from this sector). Estimating both GHG and air pollutant emissions using the same tools could delay GHG emission estimates.

480 In addition to different end uses, key emission categories can also differ substantially between air pollutant and GHG inventories, suggesting potentially different development priorities between the two. For example, by 2012, off-road mobile combustion emissions in the United States (e.g., construction, domestic shipping, agriculture, etc.) were over a quarter of $\mathrm{NO}_{x}$ emissions, but only $3 \%$ of $\mathrm{CO}_{2}$ emissions (O'Rourke et al. 2021). In the above example, increased effort to better quantify off-road 485 mobile $\mathrm{NO}_{\mathrm{x}}$ emissions, including their spatial and temporal distribution, is likely justified to better understand drivers of air pollution, but would not be a high priority for a GHG inventory. Therefore, given finite resources, key emission categories should be evaluated separately for different compounds, and data needs and development efforts should be prioritized as needed.

This point also highlights the need to clearly define emission sectors, and ideally align these definitions across chemical compounds and driver data, while also accommodating different reporting conventions and legal requirements. This is not as straightforward as it sounds. Currently, air pollution reporting for "point sources" such as power plants or refineries is often at the facility level (which is also the level at which some remote sensing validation methods can be applied), whereas IPCC GHG reporting guidelines call for separate reporting of fossil combustion, fugitive, and process emissions. One option to consider could be the expanded use of flexible reporting conventions that allow for the reporting of certain compounds by sector, which is the level at which the most accurate information may exist, and would not require a detailed split between combustion and other processes. Where resources are sufficient to allow reporting at the most detailed level, data could always be aggregated to a less detailed level. Another option would be to facilitate the use of multiple reporting standards depending on the desired use. An example is the multiple reporting formats currently available for air pollutant emissions from European countries from the EMEP Centre on Emission Inventories and Projections (https://www.ceip.at). An added challenge is that in addition to source category definitions, the chemical definitions (e.g., chemical speciation of aerosol components (BC, OC) and NMVOCs) across different sectors also need to be aligned. Chemical speciation is currently an active area of research and air pollutant inventory development will need to consider flexible guidance on appropriate emission speciation profiles as well. 
Another consideration is coordination of reported emission units. GHG emissions are commonly reported as individual compounds in units of mass (e.g., Tg) and as " $\mathrm{CO}_{2}$-equilvalants", which are calculated using Global Warming Potentials (GWPs). Differing atmospheric GHG lifetimes mean that there is no unique method of equating the climate impact of emissions. For instance, there has been exploration of numerous alternative metrics and policy frameworks focusing largely on comparing $\mathrm{CH}_{4}$ and $\mathrm{CO}_{2}$. Note, however, in idealized energy-economic model experiments, the exact $\mathrm{CH}_{4}$ metric used does not have a large impact on long-term global policy outcomes as long as there are not too many barriers to increasing $\mathrm{CH}_{4}$ mitigation over time, although there can be differing near-term and regional effects (van den Berg et al., 2015; Smith et al., 2013; Strefler et al., 2014). In contrast, for air pollutants, it was recommended at a recent IPCC expert meeting (IPCC, 2018) that air pollutant emissions in an SLCF context not be aggregated into $\mathrm{CO}_{2}$-equilvalants due to their much shorter atmospheric lifetimes (days to weeks) compared to GHGs (decades to centuries), which translates to an large range of potential comparison metrics.

520 A final aspect to consider, which is both an opportunity and a challenge, is emission uncertainty reporting. While challenging to produce, emission uncertainty estimates help to prioritize inventory improvements and inform the robustness of potential mitigation measures. The implementation of a formal uncertainty analysis, however, does not guarantee all sources of uncertainty are captured or quantified. For example, as noted in the US GHG inventory and per IPCC guidelines, quantitative

525 GHG uncertainty estimates focus only on parameter uncertainty, and do not consider structural uncertainty in models used for estimation (for example, for many agricultural emission sources) or the potential uncertainty from incorrect data reporting or missing emission sources (USEPA, 2021). In general, correlation of errors across sectors (or countries) will also generally increase uncertainty estimates, but is difficult to estimate, so might not be considered. In a formal uncertainty analysis, it is also important to flag where default emission factors may be used because sector- or region-specific values are not available (per IPCC inventory guidance), thus implying a greater uncertainty for these sources (Solazzo et al. 2021). As discussed in Section 2, air pollutant inventories have not historically incorporated emission uncertainty estimates and one challenge for the forthcoming SLCF Methodology Report will be specifying uncertainty guidance for the wide variety of methods used for air pollutant 535 inventory production, which range from complex models (e.g., MOVES in the USA for mobile sources) to direct emissions monitoring.

\section{Conclusions and Recommendations for Coordination Efforts}

Summarized in Table 1 are recommendations, particularly relevant for aligning and coordinating air pollutant and GHG emission methodologies and inventory reporting within the context of the UNFCCC and IPCC frameworks.

A key point is that, when developing emission inventory methodologies, the end goals and uses should be kept in mind. For instance, air pollutants have substantial impacts on human health (Figure 2), economies (Chantret et al. 2020), and ecosystems, resulting in different end uses of air pollutant emissions data relative to GHGs. Air pollutant and GHG emission inventories can also have different 
545 formal roles, for instance playing an integral part in regulatory and international policy frameworks in some countries, while in others inventories are just one, arguably important, part of a larger toolset. It is critical, therefore that any efforts to harmonize GHG and air pollutant emission methodologies and reporting, particularly at the international level, do not detract from the production of emissions information needed by local policy makers (e.g., high temporal and spatial resolution). In addition, given different end uses, robust communication between inventory developers, users, and researchers is critical to prioritize limited resources for inventory improvement in each country and to maximize the benefit of coordinated development and reporting of air pollutant and GHG emissions data.

Regional development priorities in terms of emission sources, impacts, and national circumstances should also be considered. For instance, air pollutant inventory development in an SLCF context should be flexible in order to be able to respond to changing priorities and context. If emissions from a once key source category are reduced, then focus may need to shift to sources that may now be relatively more important. This is reflected in current IPCC GHG inventory guidance, which recommends the use of more detailed methods for larger or quickly growing source categories. As we note above, the same level of methodological detail will not necessarily be needed for both GHG and air pollutant emissions for a given sector, although greater spatial detail is generally necessary air pollutant emissions data. For example, while IPCC guidelines for GHGs suggest estimating emissions from fuel combustion separately from fugitive emissions, for many sources and species this split can be difficult to determine. The highest priority is to have an accurate estimate of total emissions from a facility rather than spend resources to obtain finer-grained detail. This may require more flexible reporting options.

565 In addition, in countries with limited resources, inventory and data development will need to be prioritized based on local circumstances and needs. For example, a regularly updated inventory focused on priority sectors may be more useful than a more comprehensive effort that is not regularly updated due to lack of resources. Strengthening institutional and technical capacity would be an important activity in this regard. In many cases, improved inventory estimates will also require improved and 570 more detailed underlying information such as activity data, operating conditions, and emission factors relevant to region-specific conditions. For example, for emissions that have a strong dependence on environmental and operating conditions, such as fugitive emissions or products of incomplete combustion (particularly of carbonaceous aerosols), emission factors for an individual source can vary by more than one order of magnitude. Therefore, caution must be taken in applying default (i.e., lower

575 tier) emission factor assumptions to air pollutant inventories. Regardless of resources or existing inventory systems, it will be important in all regions to balance resources needed for improving underlying data streams with those required for inventory compilation and reporting. The development of such underlying information, however, is often valuable for public and private decision making in general and could be part of a larger information infrastructure development strategy (Meso et al. 2009).

580 To reduce the development burden of a new national SLCF-focused inventory in resource-limited regions, consideration could also be given to using research inventories as a starting point, such as EDGAR (Crippa et al., 2018), GAINS/ECLIPSE (Klimont et al., 2017) or CEDS (Hoesly et a. 2018; which builds on EDGAR and GAINS), or specialized datasets such as estimates of $\mathrm{CH}_{4}$ and $\mathrm{N}_{2} \mathrm{O}$ agricultural emissions from the FAOSTAT database. For some specific sources and emission species, 
such as large $\mathrm{CH}_{4}$ or $\mathrm{SO}_{2}$ sources, remote sensing estimates can also be useful adjuncts to bottom-up inventories (Schneising et al., 2020; Fioletov et al., 2016). If assessed to be credible for a specific country, these data sources could be used where resources are limited, and selectively modified or augmented where local circumstances indicate that the default assumptions used in these global estimates are not applicable. Extensive reporting requirements will be challenging for countries with limited resources or those without existing institutional arrangements to support inventory development. Methods to reduce the burden of inventory development and reporting, including the use of open-source software approaches, should be explored to enable more countries to develop emissions data that would be useful for local policymaking.

To further assist coordination efforts, definitions in underlying driving data, sources, and chemical 595 compounds should also be aligned between air pollutant and GHG inventories. It is important that this alignment does not decrease the utility of either GHG or air pollutant emissions information. In general, increased consistency in reporting of air pollutant emissions across countries would be valuable in assessing the health or economic impacts of specific sources of air pollution, assessing the impact specific mitigation policies on both air pollutant and GHG emissions, quantifying impacts from transboundary air pollution, and to more generally facilitate more frequent and accurate emissions reporting across countries. As noted above, air pollutant SLCF emissions should continue to be reported in units of mass of each compound (e.g., Tg of $\mathrm{SO}_{2}$ ) and not be converted to units of $\mathrm{CO}_{2}$-equivalents.

In terms of emission uncertainty, it would be useful to adapt the methods used for GHG uncertainty estimation to apply to air pollutant emissions where feasible. Some additional techniques may be needed, such as meta-models to characterize uncertainty in estimates from tools such as transportation sector emission models. Top-down emission estimates derived from atmospheric observations or remote sensing can also be a useful component of inventory evaluation and uncertainty analysis for both air pollutant and GHG emissions by providing an independent estimate of total emissions, albeit with its own methodological uncertainties. This will require increased communication and coordination between 610 inventory developer/compiler and research communities (Perugini, et al., 2021).

Finally, an international expert review system for air pollutant (SLCF) inventories should also be considered. Currently, intensive country reviews are incorporated into the GHG inventory reporting processes under the UNFCCC and will continue under the Paris Agreement as a means to improve inventory accuracy, quality, and transparency. Pulles (2017) has argued that, while the UNFCCC review

615 process has resulted in inventory adjustments, there was little evidence that this process has resulted in significant changes in estimated total GHG emissions (although we note that there are likely other benefits of the review process). Pulles (2017) and Hanle et al. (2019) have argued that the review process should be redesigned and streamlined. Such a redesign could be important as inventory activities expand to more countries and if international inventory reporting expands to include air pollutant SLCF emissions, which would add additional burdens to the existing review system.

We presented an overview of the history and issues associated with developing both air pollution and GHG inventories, the importance and impacts of SLCFs, and the benefits and challenges of coordinating joint GHG and air pollutant emission estimates through the development of a "SLCF 
inventory". A more thorough assessment of the potential benefits to both policy and research communities from such coordination efforts may be useful.

\section{Author Contribution}

SJS and EEM drafted text. MC conducted data analysis and visualization.

\section{Acknowledgements}

630 SJS was supported for this work by the U.S. Environmental Protection Agency. EEM was supported by an American Association for the Advancement of Science (AAAS) Science and Technology Policy Fellowship. The authors thank Bill Irving, Vince Camobreco, Robert Pinder, and Marcus Sarofim for their comments and suggestions during the manuscript development.

\section{Code/Data Availability}

635 All data used in this work was from publicly available sources. Data as complied for use in Figure 2 is supplied as a supplemental data file.

\section{Competing interests}

The authors declare no competing interests

\section{References}

Anderson, D. C., Loughner, C. P., Diskin, G., Weinheimer, A., Canty, T. P., Salawitch, R. J., Worden, H. M., Fried, A., Mikoviny, T., Wisthaler, A. and Dickerson, R. R. (2014) 'Measured and modeled CO and NOy in DISCOVER-AQ: An evaluation of emissions and chemistry over the eastern US', Atmospheric Environment, 96(0), pp. 78-87.

645 Anenberg, S. C., Miller, J., Injares, R. M., Du, L., Henze, D. K., Lacey, F., Malley, C. S., Emberson, L., Franco, V., Klimont, Z. and Heyes, C. (2017) 'Impacts and mitigation of excess diesel-related NOx emissions in 11 major vehicle markets', Nature, 545(7655), pp. 467-+.

Barnett, T. P., Hasselmann, K., Chelliah, M., Delworth, T., Hegerl, G., Jones, P., Rasmusson, E., Roeckner, E., Ropelewski, C., Santer, B. and Tett, S. (1999) 'Detection and attribution of recent climate change: A status report', Bulletin of the American Meteorological Society, 80(12), pp. 2631-2659. 
Carslaw, D. C., Beevers, S. D., Tate, J. E., Westmoreland, E. J. and Williams, M. L. (2011) 'Recent evidence concerning higher NOx emissions from passenger cars and light duty vehicles', Atmospheric Environment, 45(39), pp. 7053-7063.

Chantret, F., Chateau, J., Dellink, R., Durand-Lasserve, O. \& Lanzi, E. 2020. Can Better Technologies

Avoid All Air Pollution Damages to the Global Economy? Climatic Change, 163, 1463-1480. doi: 10.1007/s10584-019-02631-2.

Crippa, M., Guizzardi, D., Muntean, M., Schaaf, E., Dentener, F., van Aardenne, J. A., Monni, S., Doering, U., Olivier, J. G. J., Pagliari, V. and Janssens-Maenhout, G. (2018) 'Gridded emissions of air pollutants for the period 1970-2012 within EDGAR v4.3.2', Earth System Science Data, 10(4), pp. 1987-2013.

Etminan, M., Myhre, G., Highwood, E. J. and Shine, K. P. (2016) 'Radiative forcing of carbon dioxide, methane, and nitrous oxide: A significant revision of the methane radiative forcing', Geophysical Research Letters, 43(24), pp. 12614-12623.

Feng, L. Y., Smith, S. J., Braun, C., Crippa, M., Gidden, M. J., Hoesly, R., Klimont, Z., van Marle, M., van den Berg, M. and van der Werf, G. R. (2020) 'The generation of gridded emissions data for CMIP6', Geoscientific Model Development, 13(2), pp. 461-482.

Feng, Y. and Penner, J. E. (2007) 'Global modeling of nitrate and ammonium: Interaction of aerosols and tropospheric chemistry', Journal of Geophysical Research-Atmospheres, 112(D1).

Fioletov, V. E., McLinden, C. A., Krotkov, N., Li, C., Joiner, J., Theys, N., Carn, S. and Moran, M. D. 670 (2016) 'A global catalogue of large SO2 sources and emissions derived from the Ozone Monitoring Instrument', Atmospheric Chemistry and Physics, 16(18), pp. 11497-11519.

GBD Collaborators (2020) 'Global burden of 87 risk factors in 204 countries and territories, 1990-2019: a systematic analysis for the Global Burden of Disease Study 2019', The Lancet, 396(10258), pp. 12231249.

675 Ghan, S. J., Smith, S. J., Wang, M. H., Zhang, K., Pringle, K. J., Carslaw, K. S., Pierce, J. R., Bauer, S. E. and Adams, P. J. (2013) 'A simple model of global aerosol indirect effects', Journal of Geophysical Research-Atmospheres, 118(12), pp. 6688-6707.

Hand, J. L., Schichtel, B. A., Malm, W. C. and Pitchford, M. L. (2012) 'Particulate sulfate ion concentration and SO2 emission trends in the United States from the early 1990s through 2010',

680 Atmospheric Chemistry and Physics, 12(21), pp. 10353-10365.

Hanle, L., Gillenwater, M., Pulles, T. and Radunsky, K. (2019) Challenges and Proposed Reforms to the UNFCCC Expert Review Process for the Enhanced Transparency Framework.

Hassler, B., McDonald, B. C., Frost, G. J., Borbon, A., Carslaw, D. C., Civerolo, K., Granier, C., Monks, P. S., Monks, S., Parrish, D. D., Pollack, I. B., Rosenlof, K. H., et al. (2016) 'Analysis of long685 term observations of NOx and CO in megacities and application to constraining emissions inventories', Geophysical Research Letters, 43(18), pp. 9920-9930. 
Hoesly, R. M., Smith, S. J., Feng, L. Y., Klimont, Z., Janssens-Maenhout, G., Pitkanen, T., Seibert, J. J., Vu, L., Andres, R. J., Bolt, R. M., Bond, T. C., Dawidowski, L., et al. (2018) 'Historical (1750-2014) anthropogenic emissions of reactive gases and aerosols from the Community Emissions Data System (CEDS)', Geoscientific Model Development, 11(1), pp. 369-408.

Huneeus, N., van der Gon, H. D., Castesana, P., Menares, C., Granier, C., Granier, L., Alonso, M., Andrade, M. D., Dawidowski, L., Gallardo, L., Gomez, D., Klimont, Z., et al. (2020) 'Evaluation of anthropogenic air pollutant emission inventories for South America at national and city scale', Atmospheric Environment, 235.

695 Ibrahim, N., Sugar, L., Hoornweg, D. and Kennedy, C. (2012) 'Greenhouse gas emissions from cities: comparison of international inventory frameworks', Local Environment, 17(2), pp. 223-241.

IPCC (2006) 2006 IPCC Guidelines for National Greenhouse Gas Inventories, Japan: National Greenhouse Gas Inventories Programme (IGES).

IPCC (2019) 2019 Refinement to the 2006 IPCC Guidelines for National Greenhouse Gas Inventories,

700 Japan: National Greenhouse Gas Inventories Programme (IGES).

IPCC (2018) Report of the Expert Meeting on Short-Lived Climate Forcers, Japan: IGES (ISBN 978-488788-218-8.

Janssens-Maenhout, G., Crippa, M., Guizzardi, D., Dentener, F., Muntean, M., Pouliot, G., Keating, T., Zhang, Q., Kurokawa, J., Wankmuller, R., van der Gon, H. D., Kuenen, J. J. P., et al. (2015)

705 'HTAP_v2.2: a mosaic of regional and global emission grid maps for 2008 and 2010 to study hemispheric transport of air pollution', Atmospheric Chemistry and Physics, 15(19), pp. 11411-11432.

Klimont, Z., Kupiainen, K., Heyes, C., Purohit, P., Cofala, J., Rafaj, P., Borken-Kleefeld, J. and Schopp, W. (2017) 'Global anthropogenic emissions of particulate matter including black carbon', Atmospheric Chemistry and Physics, 17(14), pp. 8681-8723.

710 Lelieveld, J., Klingmuller, K., Pozzer, A., Burnett, R. T., Haines, A. and Ramanathan, V. (2019) 'Effects of fossil fuel and total anthropogenic emission removal on public health and climate', Proceedings of the National Academy of Sciences of the United States of America, 116(15), pp. 71927197.

Liu, Y. M. and Wang, T. (2020) 'Worsening urban ozone pollution in China from 2013 to 2017-Part 2: 715 The effects of emission changes and implications for multi-pollutant control', Atmospheric Chemistry and Physics, 20(11), pp. 6323-6337.

McDuffie E.E., R.V. Martin, J. Spadaro, R. Burnett, S.J. Smith, P. O'Rourke, and M. Hammer, et al. (2021) " Source sector and fuel contributions to ambient PM2.5 and attributable mortality across multiple spatial scales." Nature Communications 12, 3594. doi: 10.1038/s41467-021-23853-y

720 Maasakkers, J. D., Jacob, D. J., Sulprizio, M. P., Turner, A. J., Weitz, M., Wirth, T., Hight, C., Defigueiredo, M., Desai, M., Schmeltz, R., Hockstad, L., Bloom, A. A., Bowman, K. W., Jeong, S. \& 
Fischer, M. L. 2016. Gridded National Inventory of Us Methane Emissions. Environmental Science \& Technology, 50, 13123-13133. doi: 10.1021/acs.est.6b02878.

Mannucci, P. M., Harari, S., Martinelli, I. and Franchini, M. (2015) 'Effects on health of air pollution: a narrative review', Internal and Emergency Medicine, 10(6), pp. 657-662.

Meso, P., Musa, P., Straub, D. and Mbarika, V., 2009. Information infrastructure, governance, and socio-economic development in developing countries. European Journal of Information Systems, 18(1), pp.52-65.

Minx, J. C., Lamb, W. F., Andrew, R. M., Canadell, J. G., Crippa, M., Döbbeling, N., Forster, P. M., 730 Guizzardi, D., Olivier, J., Peters, G. P., Pongratz, J., Reisinger, A., Rigby, M., Saunois, M., Smith, S. J., Solazzo, E., and Tian, H. (2021) A comprehensive dataset for global, regional and national greenhouse gas emissions by sector 1970-2019, Earth Syst. Sci. Data Discuss. https://doi.org/10.5194/essd-2021228, accepted,

Myhre, G., Shindell, D., Bréon, F.-M., Collins, W., Fuglestvedt, J., Huang, J., Koch, D., Lamarque, J.-

735 F., Lee, D., Mendoza, B., Nakajima, T., Robock, A., et al. (2013) 'Anthropogenic and Natural Radiative Forcing', in Stocker, T.F., Qin, D., Plattner, G.-K., Tignor, M., Allen, S.K., Boschung, J., Nauels, A., Xia, Y., Bex, V. and Midgley, P.M. (eds.) Climate Change 2013: The Physical Science Basis. Contribution of Working Group I to the Fifth Assessment Report of the Intergovernmental Panel on Climate Change. Cambridge, United Kingdom and New York, NY, USA: Cambridge University Press, pp. 659-740.

Naik, V., S. Szopa, B. Adhikary, P. Artaxo, T. Berntsen, W. D. Collins, S. Fuzzi, L. Gallardo, A. Kiendler Scharr, Z. Klimont, H. Liao, N. Unger, P. Zanis, 2021, Short-Lived Climate Forcers. In: Climate Change 2021: The Physical Science Basis. Contribution of Working Group I to the Sixth Assessment Report of the Intergovernmental Panel on Climate Change [Masson-Delmotte, V., P. Zhai,

745 A. Pirani, S. L. Connors, C. Péan, S. Berger, N. Caud, Y. Chen, L. Goldfarb, M. I. Gomis, M. Huang, K. Leitzell, E. Lonnoy, J. B. R. Matthews, T. K. Maycock, T. Waterfield, O. Yelekçi, R. Yu and B. Zhou (eds.)]. Cambridge University Press. In Press

O'Neill, B. C., Tebaldi, C., van Vuuren, D. P., Eyring, V., Friedlingstein, P., Hurtt, G., Knutti, R., Kriegler, E., Lamarque, J. F., Lowe, J., Meehl, G. A., Moss, R., et al. (2016) 'The Scenario Model

750 Intercomparison Project (ScenarioMIP) for CMIP6', Geoscientific Model Development, 9(9), pp. 34613482 .

O'Rourke, P. R, Smith, S. J., Mott, A., Ahsan, H., McDuffie, E. E., Crippa, M., Klimont, S., McDonald, B., Z., Wang, Nicholson, M. B, Feng, L., and Hoesly, R. M. (2021, February 05). Community Emissions Data System (Version Feb-05-2021). Zenodo. http://doi.org/10.5281/zenodo.4509372

755 Perugini, L., Pellis, G., Grassi, G., Ciais, P., Dolman, H., House, J. I., Peters, G. P., Smith, P., Gunther, D. and Peylin, P. (2021) 'Emerging reporting and verification needs under the Paris Agreement: How can the research community effectively contribute?', Environmental Science \& Policy, 122, pp. 116126. 
Pulles, T. (2017) 'Did the UNFCCC review process improve the national GHG inventory submissions?',

Carbon Management, 8(1), pp. 19-31.

Schneising, O., Buchwitz, M., Reuter, M., Vanselow, S., Bovensmann, H. and Burrows, J. P. (2020)

'Remote sensing of methane leakage from natural gas and petroleum systems revisited', Atmos. Chem. Phys., 20(15), pp. 9169-9182.

Smith, S. J., Karas, J., Edmonds, J., Eom, J. and Mizrahi, A. (2013) 'Sensitivity of multi-gas climate policy to emission metrics', Climatic Change, 117(4), pp. 663-675.

Smith, S. J. and Mizrahi, A. (2013) 'Near-term climate mitigation by short-lived forcers', Proceedings of the National Academy of Sciences, 110(35), pp. 14202-14206.

Solazzo, E., Crippa, M., Guizzardi, D., Muntean, M., Choulga, M., and Janssens-Maenhout, G.: Uncertainties in the Emissions Database for Global Atmospheric Research (EDGAR) emission

770 inventory of greenhouse gases, Atmos. Chem. Phys., 21, 5655-5683, https://doi.org/10.5194/acp-215655-2021, 2021

Soriano, J. B., Kendrick, P. J., Paulson, K. R., Gupta, V., Vos, T. and Collaborators, G. C. R. D. (2020) 'Prevalence and attributable health burden of chronic respiratory diseases, 1990-2017: a systematic analysis for the Global Burden of Disease Study 2017', Lancet Respiratory Medicine, 8(6), pp. 585-596.

775 Stevenson, D. S., Zhao, A., Naik, V., O'Connor, F. M., Tilmes, S., Zeng, G., Murray, L. T., Collins, W. J., Griffiths, P. T., Shim, S., Horowitz, L. W., Sentman, L. T., and Emmons, L.: Trends in global tropospheric hydroxyl radical and methane lifetime since 1850 from AerChemMIP, Atmos. Chem. Phys., 20, 12905-12920, https://doi.org/10.5194/acp-20-12905-2020, 2020

Stjern, C. W., Samset, B. H., Myhre, G., Forster, P. M., Hodnebrog, O., Andrews, T., Boucher, O., 780 Faluvegi, G., Iversen, T., Kasoar, M., Kharin, V., Kirkevag, A., et al. (2017) 'Rapid Adjustments Cause Weak Surface Temperature Response to Increased Black Carbon Concentrations', Journal of Geophysical Research-Atmospheres, 122(21), pp. 11462-11481.

Stone, D. A., Allen, M. R., Stott, P. A., Pall, P., Min, S. K., Nozawa, T. and Yukimoto, S. (2009) 'The Detection and Attribution of Human Influence on Climate', Annual Review of Environment and

785 Resources, 34, pp. 1-16.

Strefler, J., Luderer, G., Aboumahboub, T. and Kriegler, E. (2014) 'Economic impacts of alternative greenhouse gas emission metrics: a model-based assessment', Climatic Change, 125(3-4), pp. 319-331.

USEPA (2021) Inventory of U.S. Greenhouse Gas Emissions and SInks: 1990-2019, USA: USEPAEPA 430-R-21-005).

790 van den Berg, M., Hof, A. F., van Vliet, J. and van Vuuren, D. P. (2015) 'Impact of the choice of emission metric on greenhouse gas abatement and costs', Environmental Research Letters, 10(2).

van Marle, M. J. E., Kloster, S., Magi, B. I., Marlon, J. R., Daniau, A.-L., Field, R. D., Arneth, A., Forrest, M., Hantson, S., Kehrwald, N. M., Knorr, W., Lasslop, G., Li, F., Mangeon, S., Yue, C., Kaiser, J. W., and van der Werf, G. R.: Historic global biomass burning emissions for CMIP6 (BB4CMIP) 
795 based on merging satellite observations with proxies and fire models (1750-2015), Geosci. Model Dev., 10, 3329-3357, https://doi.org/10.5194/gmd-10-3329-2017, 2017

Xing, J., Mathur, R., Pleim, J., Hogrefe, C., Gan, C. M., Wong, D. C., Wei, C., Gilliam, R. and Pouliot, G. (2015) 'Observations and modeling of air quality trends over 1990-2010 across the Northern Hemisphere: China, the United States and Europe', Atmospheric Chemistry and Physics, 15(5), pp.

$800 \quad 2723-2747$.

Zheng, B., Tong, D., Li, M., Liu, F., Hong, C., Geng, G., Li, H., Li, X., Peng, L., Qi, J., Yan, L., Zhang, Y., et al. (2018a) 'Trends in China's anthropogenic emissions since 2010 as the consequence of clean air actions', Atmos. Chem. Phys., 18(19), pp. 14095-14111.

Zheng, B., Tong, D., Li, M., Liu, F., Hong, C. P., Geng, G. N., Li, H. Y., Li, X., Peng, L. Q., Qi, J., 805 Yan, L., Zhang, Y. X., et al. (2018b) 'Trends in China's anthropogenic emissions since 2010 as the consequence of clean air actions', Atmospheric Chemistry and Physics, 18(19), pp. 14095-14111.

Zimmerle, D. J., Williams, L. L., Vaughn, T. L., Quinn, C., Subramanian, R., Duggan, G. P., Willson, B., Opsomer, J. D., Marchese, A. J., Martinez, D. M. and Robinson, A. L. (2015) 'Methane Emissions from the Natural Gas Transmission and Storage System in the United States', Environmental Science \& 810 Technology, 49(15), pp. 9374-9383. 


\section{Table 1: Recommendations for Coordination Efforts}

- Account for the different end uses of air pollutant and GHG emissions inventory data while maintaining the useability of each (e.g., consider necessary sectoral, spatial, and temporal data resolutions).

- Enhance communication between air pollutant and GHG inventory developer, research, and policy communities

- Consider regional development priorities.

- Understand the key emission sources across regions and compounds to prioritize development/reporting and data collection resources.

- Develop flexible reporting protocols and methodologies that allow for accurate reporting but that are not overly burdensome. For example, the use of the IPCC tier approach (e.g., higher tiers needed for some emission species in a particular sector, but lower tiers might be acceptable for other species).

- Consider the use of research inventories as a starting point

- Align, and publicly document, definitions of sectoral, chemical speciation, and activity driver data between air pollutant and GHG inventories.

- Air pollutant SLCFs should not be reported in units of $\mathrm{CO}_{2^{-}}$ equilvalants.

- Draw on existing GHG inventory methodologies to provide estimates of air pollutant emission uncertainties.

- An international expert review system for air pollutant 'SLCF inventories' should be considered. 


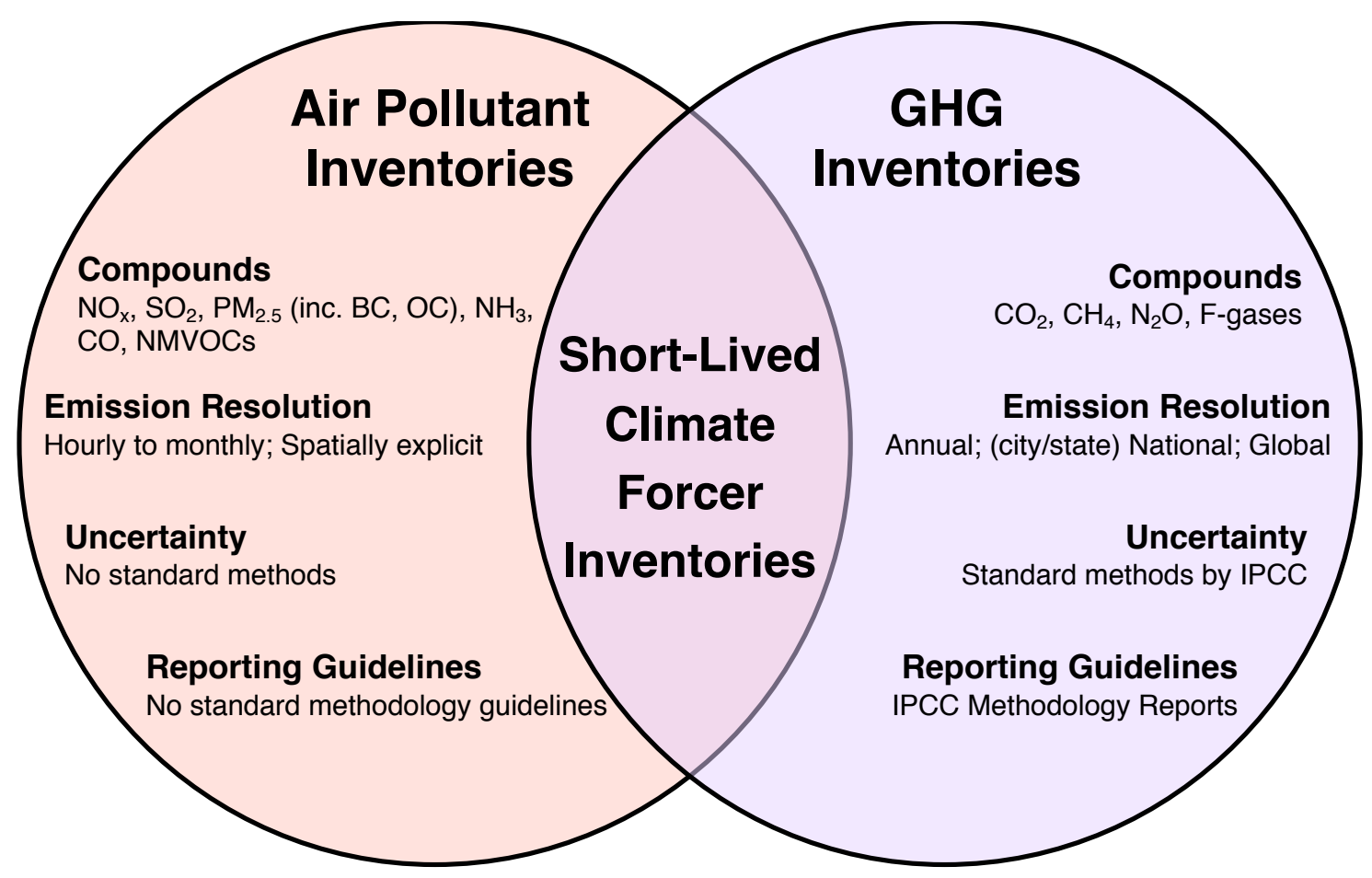

Figure 1: Schematic diagram illustrating the main characteristics of greenhouse gas (GHGs) vs air pollutant inventories, also highlighting overlap in characteristics with Short-Lived Climate Forcer (SLCF) inventories. As discussed in the main text, a "SLCF inventory" is largely a matter of context rather than a distinct category of inventory data. Note also that some GHGs and all air pollutants listed above are considered SLCF compounds. 


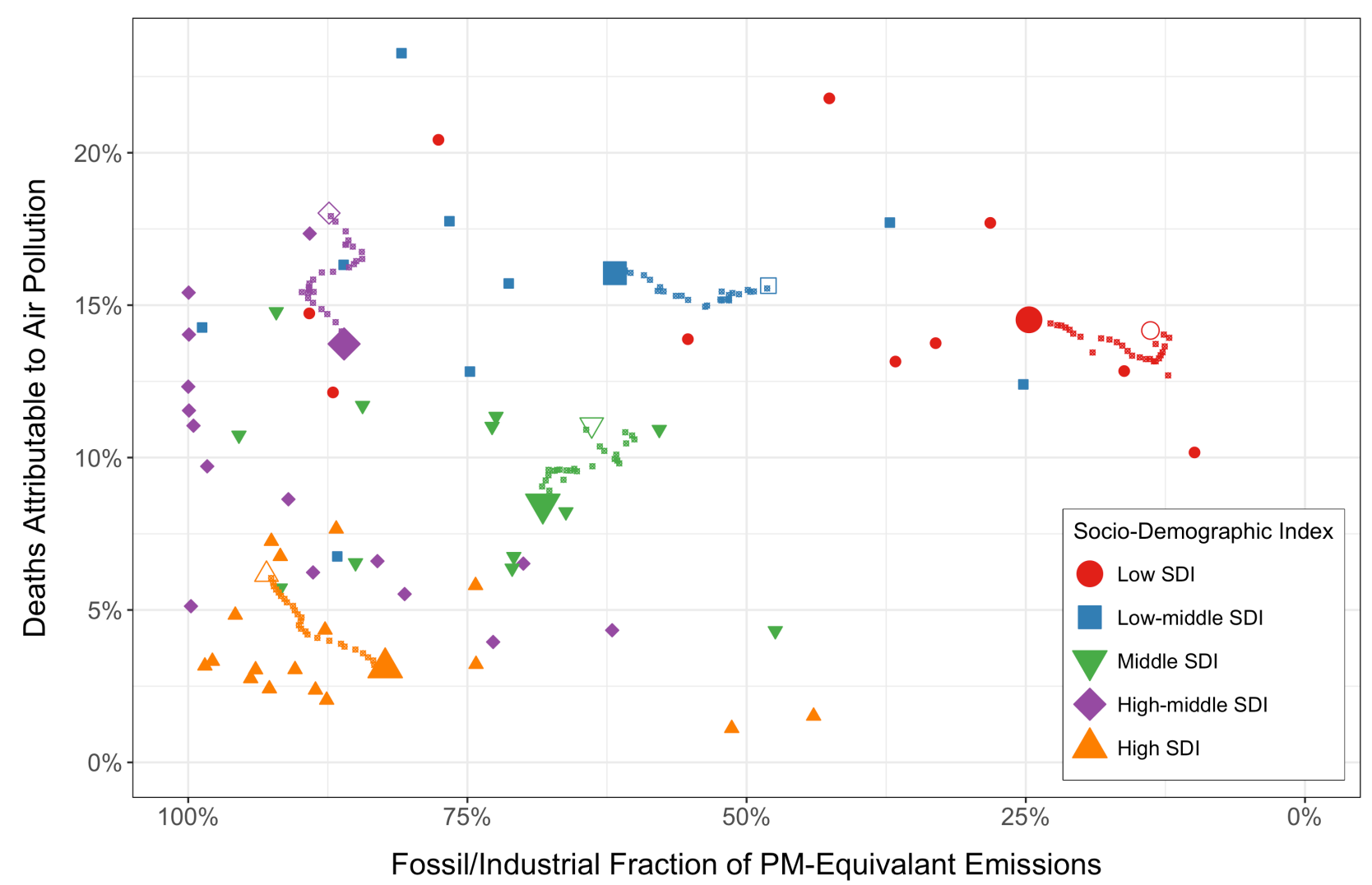

Figure 2: Illustrative figure showing the relationship between emissions source and the fraction of 'all cause' deaths attributable to annual air pollution (e.g., outdoor/indoor $\mathrm{PM}_{2.5}$ and $\mathrm{O}_{3}$ ) exposure over time and by socio-demographic category. Fraction of all deaths in 2019 attributable to annual air pollution exposure (y-axis) by major Socio-Demographic Index (SDI) groups (large symbols) from the GBD project (GBD Chronic Respiratory Disease Collaborators2020) plotted against the fraction of equivalent particulate matter (PM) emissions from fossil/industrial sources (van Marle et. al 2017, O'Rourke et al. 2021, see Appendix for definitions). The largest countries within each SDI group are shown as small individual symbols. The trajectory over 1990 (open symbols) to 2019 (large filled symbols) for each country SDI group is shown by the smaller trailing symbols. Countries in the lower left position have the lowest mortality from air pollution with particulates largely from fossil and industrial sources. Countries in the upper right have a higher disease burden from air pollution and particulates that are largely from non-fossil sources such as forest and grassland fires and household use of solid biofuels. 


\section{Appendix - Data sources and methodology for Figure 2}

\section{A.1 Equivalent Particulate Matter (PM) Emissions}

Illustrating the relationship between emissions and air pollution-related mortalities, as we have done in Figure 2, is challenging because of the complexities discussed in the main text. In order to show the general sources of particulate pollution in different countries over time we developed a metric we call equivalent particulate emissions. This represents a generic estimate of how much particulate matter is produced by emissions in each country.

This metric is constructed by summing the primary BC and OC particulate emissions together with an estimate of secondary particulate formation obtained by multiplying each precursor emission species by a multiplier that represents the amount of particulate (by weight) that is produced globally by that emission species. Molecular conversions are applied as necessary. For example, each $\mathrm{kg}$ of $\mathrm{SO}_{2}$ gas that is converted into sulfate aerosols results in $1.8 \mathrm{~kg}$ of ammonium bisulfuate aerosol, but we assume that only $55 \%$ of emitted $\mathrm{SO}_{2}$ is converted into sulfate aerosol as the remainder is lost through wet or dry deposition (Ghan et al. 2013).

Sources for conversion factors used are provided in table A-1. There is uncertainty and spatial variation in nearly all of these conversion factors, but the globally representative values used here serve to provide a rough estimate of how much particulate matter is produced by emissions of each species and allow us to provide an estimate of the fraction of particulate matter originating from fossil/industrial sources as shown in Figure 2.

For Figure 2 we required the fraction of PM-equivalent emissions that are from fossil sources. Nonfossil/industrial emissions were considered to be the following sources: grassland burning, forest burning (including deforestation), agricultural waste burning on fields, and all combustion of solid biomass fuels. All other emissions were considered fossil sources. We have categorized all anthropogenic emissions as "fossil/industrial", including emissions from agricultural systems, which are largely, although not entirely, facilitated by fossil-fueled inputs and industrial-scale operations (e.g., fertilizer application, confined animal feeding operations, etc.). For primary OC emissions, the conversion is from carbon units, used in the inventory data, to total $\mathrm{OC}$ weight.

We note that secondary organic aerosols (SOA) due to anthropogenic NMVOC emissions are not included as we did not find a definitive source for this conversion (although we note that a large portion of anthropogenic SOA originates from biogenic VOC emissions). Mineral $\mathrm{PM}_{2.5}$ emissions, such as flyash from coal combustion, are also not included because these are not available in global emission inventories by country.

The x-axis of figure 2 indicates the fraction of total PM-equivalent emissions that are from fossil and industrial sources. As noted above we consider fossil/industrial emissions to be all emissions excluding the following:

- Solid biomass CEDS (anthropogenic) emissions across all sectors

- 5C_Waste-incineration and open burning of waste (CEDS) 
- All open burning emissions (forest fires, grassland files, ag waste burning on fields) from GFED We recognize that there is a small portion of emissions from liquid and gaseous fuels that are derived from biofuels that would be included in the fossil/industrial faction, but these are small. Similarly, emissions from both waste incineration and open burning result from a combination of fossil (e.g., plastics) and non-fossil (paper, and food) sources.

\begin{tabular}{llll} 
Emission & $\begin{array}{l}\text { Emission } \\
\text { Unit }\end{array}$ & $\begin{array}{l}\text { Conversion } \\
\text { Factor }\end{array}$ & Source \\
\hline $\mathrm{SO}_{2}$ & $\mathrm{kt} \mathrm{SO}_{2}$ & 0.99 & (Ghan et al., 2013) \\
$\mathrm{NO}_{\mathrm{x}}$ & $\mathrm{kt} \mathrm{NO}_{2}$ & 0.61 & (Feng and Penner, 2007) \\
$\mathrm{NH}_{3}$ & $\mathrm{kt} \mathrm{NH}$ & 0.5 & (Feng and Penner, 2007) \\
$\mathrm{BC}$ & $\mathrm{ktC}$ & 1 & NA \\
OC_biomass & $\mathrm{ktC}$ & 1.8 & (Klimont et al., 2017) \\
OC_fossil & $\mathrm{ktC}$ & 1.3 & (Klimont et al., 2017))
\end{tabular}

Table A-2 - Conversion factors used for the Equivalent-PM emissions calculation. The factor converts emissions in terms of weight units used in the emission inventory to weight of particulate matter accounting for the fraction of emissions that are converted to aerosol and changes in molecular weight.

880 A.2 Health Impacts of Air Pollution

Health impact results used in this work were downloaded from: $h \mathrm{ttp}: / /$ ghdx.healthdata.org/gbd-resultstool (downloaded Feb 21, 2021), as documented in GBD 2019 Risk Factor Collaborators (2020). Shown in Figure 1 is the ratio of deaths from "Air pollution" exposure to deaths from "All_Cause". This ratio represents the deaths that are attributable to annual exposure to total air pollution (indoor $\mathrm{PM}_{2.5}$, outdoor

$885 \mathrm{PM}_{2.5}$, and $\mathrm{O}_{3}$; caused by type II diabetes, stroke, chronic obstructive pulmonary disorder, lower respiratory infections, ischemic heart disease, lung cancer, and neonatal disorders [low birth weight, pre-term births]) relative to the total number of deaths caused by 369 diseases and injuries assessed by the 2019 GBD. Changes in this ratio overtime may reflect changes in both the number of deaths attributable to air pollution (due to changes in both air pollution and baseline mortality rates), as well as 890 trends in the remaining causes of death in particular countries.

The emissions and health impact data, as processed for Figure 2, is provided as a supplementary data file. 